EPJ Web of Conferences 66, 00003 (2014)

DOI: $10.1051 /$ epjconf/ 20146600003

(C) Owned by the authors, published by EDP Sciences, 2014

\title{
IBA-Europhysics Prize in Applied Nuclear Science and Nuclear Methods in Medicine
}

\author{
I J Douglas MacGregor ${ }^{1,2}$ \\ ${ }^{1}$ Nuclear Physics Board of the European Physical Society \\ ${ }^{2}$ SUPA, School of Physics and Astronomy, University of Glasgow, Glasgow G12 8QQ, UK
}

\begin{abstract}
The Nuclear Physics Board of the European Physical Society is pleased to announce that the 2013 IBA-Europhysics Prize in Applied Nuclear Science and Nuclear Methods in Medicine is awarded to Prof. Marco Durante, Director of the Biophysics Department at GSI Helmholtz Center (Darmstadt, Germany); Professor at the Technical University of Darmstadt (Germany) and Adjunct Professor at the Temple University, Philadelphia, USA. The prize was presented in the closing Session of the INPC 2013 conference by Mr. Thomas Servais, R\&D Manager for Accelerator Development at the IBA group, who sponsor the IBA Europhysics Prize. The Prize Diploma was presented by Dr. I J Douglas MacGregor, Chair-elect of the EPS Nuclear Physics Division and Chair of the IBA Prize committee.
\end{abstract}

\section{The Nuclear Physics Division of the EPS}

The European Physical Society (EPS) is a learned society whose aims are to promote physics in a European context and to provide a forum for individual physicists across Europe to exchange ideas. The Nuclear Physics Division was established four decades ago to assist the advancement and dissemination of knowledge of Nuclear Physics. It promotes the subject through the organisation of conferences and summer schools, by furthering the exchange of scientists and the award of major prizes to recognise outstanding achievement in the subject.

The Division has recently established a series of 3-yearly European Nuclear Physics conferences spanning the full breadth of the subject. The $1^{\text {st }}$ conference, in 2009, was held jointly with the German Physical Society (DPG). The $2^{\text {nd }}$ European Nuclear Physics conference was independently organised in Bucharest, $17^{\text {th }}-21^{\text {st }}$ September 2012. The $3^{\text {rd }}$ conference will be held in Groningen in September 2015. The Division also has a long-established biennial series of Divisional Conferences on Nuclear Physics in Astrophysics (NPA). The most recent, NPA VI, was held in Lisbon from $19^{\text {th }}-24^{\text {th }}$ May 2013 and the $7^{\text {th }}$ NPA conference will be held in York in May 2015. In a new initiative, the Division is embarking on a new series of facility-based conferences. The first of these, on the Science and Technology of FAIR, will be held at GSI in 2014.

The Division offers three major prizes: The IBA Europhysics Prize for Applied Nuclear Science and Nuclear Methods in Medicine ; The Lise Meitner Prize for outstanding contributions to Nuclear Science and a new triennial prize for the best $\mathrm{PhD}$ dissertation in nuclear physics in Europe. Further details of the work of the Nuclear Physics Division can be found on our website [1]. 


\section{The IBA- Europhysics Prize}

The IBA-Europhysics Prize is awarded biannually in odd years to one or more researchers who have made outstanding contributions to Applied Nuclear Science and Nuclear Methods in Medicine in Europe. It is sponsored by the IBA group.

\section{Prof. Marco Durante}
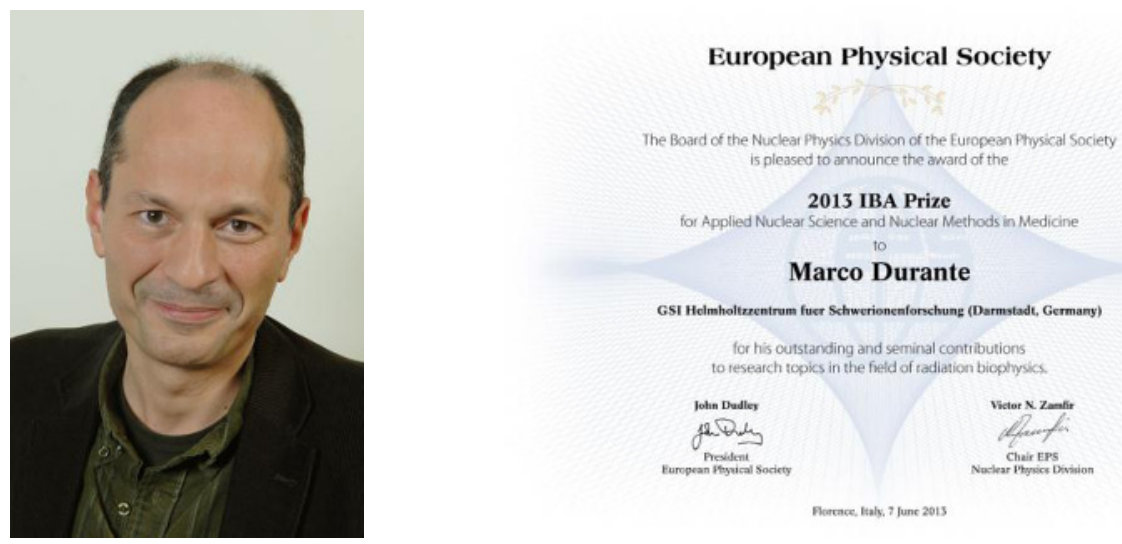

Figure 1. Prof. Marco Durante, Winner of the 2013 IBA Prize together with his Prize Diploma.

The 2013 IBA Prize for Applied Nuclear Science and Nuclear Methods in Medicine is awarded to Prof. Marco Durante "for his outstanding and seminal contributions to research topics in the field of radiation biophysics, including work in clinical and space radiobiology, particle genetic damage and therapy, and his valuable activities in the scientific community."

Below are a few highlights of Prof. Durante's work. Prof. Durante has had a long and distinguished career in radiation biophysics. His Ph.D. (Naples 1988) was carried out in this field and since then he has gone on to become a world-leading authority.

Before the development of microbeams he proposed a method to detect and measure biological effects of charged-particles using solid state nuclear track detectors. Mammalian cells grown on thin mylar films were exposed to accelerated He-ions. Cells were then incubated for colony formation, and the colonies traced back to the recorded cell images to determine the fate of the single cells and the fraction surviving irradiation.

Prof Durante has spent many years analysing chromosomal aberrations induced by heavy ions. At NASA Johnson Space Center, he combined the methods of premature chromosome condensation (PCC) and fluorescence in situ hybridization (FISH) to study the formation of chromosomal aberrations in human cells. The results proved that the kinetics of formation of chromosomal aberrations after heavy ions has the same mechanism and follows the same shape as for sparsely ionizing radiation, although quantitative differences were observed. Later he applied variations of this technique (mFISH, mBAND, and RxFISH) to cells exposed to heavy ions and his studies pointed out qualitative differences in the aberrations induced by heavy ions, particularly a large increase in complex-type exchanges. 
He has been instrumental in the development of a novel technique for premature chromosome condensation, based on the action of a phosphatise inhibitor, calyculin A, which he developed together with Dr. Eisuke Gotoh. The method is now largely used in biodosimetry, especially after exposure to heavy ions. A review paper by Prof. Durante and Dr. Gotoh [2] summarizes the results.

Prof Durante is a leading expert in biological effects of space radiation, and advises ESA on radiobiology. Since 2000 he has led a large International Collaboration including European, Japanese and US research centers for studying biological effects of shielded heavy ions. These studies helped demonstrate that light, hydrogen rich materials, such as polyethylene, are more effective than high-Z materials for protection from cosmic rays. Shielding tests with new materials are currently being carried out on the International Space Station. He has worked on biodosimetry in astronauts and has analysed blood cells from Russian cosmonauts involved in long-term space missions (up to 750 days in space). The study of chromosomal aberrations led to the interesting observation that the radiosensitivity decreases in later flights compared to the first mission. These results may point to an acquired radioresistance induced by exposure to space flight. He has published review papers on space radiation research in leading International journals, including a recent review in Lancet Oncology [3].

Prof. Durante's expertise in the biophysics of heavy ions has also been applied in several studies dealing with cancer hadrontherapy. At the Chiba National Institute for Radiological Center (Japan), he studied tissue samples from similar patients treated with either X-rays or high-energy carbon ions. The comparison demonstrated that, although $\mathrm{C}$-ions are more effective in the induction of genetic damage per unit dose, the damage in the patient is reduced, because of the better dose localization and minimized normal tissue damage in hadrontherapy. This research is continuing at GSI where recent work has focused on the difficulties of moving targets.

His work has previously been recognised through the ESA Team achievement award, ENEIDE mission (2005), Galileo Galilei Award in Medical Physics, European Federation of Organizations for Medical Physics (2005), 60 ${ }^{\text {th }}$ Timofeeff-Ressovsky medal, Russian Academy of Sciences (2010) and the $8^{\text {th }}$ Warren K. Sinclair award, US National Academy of Sciences (2011).

In conclusion Prof Durante has made an outstanding contribution to our understanding of radiation biophysics and is a very worthy winner of the 2013 IBA Prize.

\section{Acknowledgements}

The Board of the EPS Nuclear Physics Division would like to thank the organisers of the INPC 2013 conference for providing an opportunity to present the 2013 IBA-Europhysics Prize to Prof. Durante in front of a large international audience of nuclear physicsts. This provided a very appropriate occasion to make the award.

\section{References}

1. EPS Nuclear Physics Division website, http://www.eps.org/?page=npd

2. Chromosome condensation outside of mitosis: mechanisms and new tools, E. Gotoh and M. Durante, J Cell Physiol 209, 297 (2006)

3. Cancer risk from exposure to galactic cosmic rays: implications for space exploration by human beings, F. A. Cucinotta and M. Durante, Lancet Oncology, 7, 431 (2006) 
